\title{
Qrs-Complex Fragmentations and Right Ventricular Infarction in the Presence of Inferior Infarction with Triple-Vessels Disease; Bad Initials but a Good Outcome
}

\author{
Yasser Mohammed Hassanain Elsayed \\ Critical Care Unit, Al-Rodah Central Hospital, Damietta Health Affairs, Egyptian Ministry of Health (MOH), Damietta, Egypt.
}

Corresponding Author: Yasser Mohammed Hassanain Elsayed, Critical Care Unit, Al-Rodah Central Hospital, Damietta Health Affairs, Egyptian Ministry of Health (MOH), Damietta, Egypt.

\section{Received date: October 04, 2021; Accepted date: December 17, 2021; Published date: January 01, 2022}

Citation: Elsayed Y M H, (2022). Qrs-Complex Fragmentations and Right Ventricular Infarction in the Presence of Inferior Infarction with TripleVessels Disease; Bad Initials but a Good Outcome. J Thoracic Disease and Cardiothoracic Surgery, 3(1); DOI:10.31579/2693-2156/032

Copyright: (C) 2022, Elsayed Y M H. This is an open access article distributed under the Creative Commons Attribution License, which permits unrestricted use, distribution, and reproduction in any medium, provided the original work is properly cited.

\begin{abstract}
Rationale: The term "fragmentation of the QRS complex" denotes the existence of high-frequency potentials (spikes) in the QRS-complex. It is either a marker for cardiac structural diseases inducing biventricular hypertrophy or any condition interfering with the normally homogeneous depolarization status inside the myocardium. An associated right ventricular infarction with inferior infarction maybe carry a risk impact and serious complications.

Patient concerns: A 64-year-old married, farmer, heavy smoker, Egyptian male patient presented with acute severe chest pain and inferior with right ventricular ST-segment elevation myocardial infarction and fragmentation of the QRS complex.

Diagnosis: QRS-complex fragmentations and right ventricular infarction in the presence of inferior infarction with the triple-vessels disease.

Interventions: Electrocardiography, oxygenation, streptokinase intravenous infusion, echocardiography, and percutaneous transluminal coronary angioplasty.

Outcomes: Dramatic response of acute inferior with right ventricular ST-segment elevation myocardial infarction and QRS-complex fragmentations to streptokinase.

Lessons: Despite the presence of inferior and right ventricular ST-segment elevation myocardial infarction with QRScomplex fragmentations, but there is no correlation with the severity of the disease. Dramatic clinical and electrocardiographic response signifying the role of streptokinase and fibrinolytic. The presence of fragmentation of the QRS-complex may have a bidirectional impact from seriousness to complications.
\end{abstract}

Keywords: QRS-complex fragmentations; right ventricular infarction; inferior infarction; triple-vessels disease; percutaneous transluminal coronary angioplasty

\section{Introduction}

The term "fragmentation of the QRS-complex" or "fragmented QRS" (fQRS) point to the existence of high-frequency potentials (spikes) in the QRS-complex [1]. The expression was first described in 1973 in reporting of an experimental study on canine hearts where coronary artery obstruction motivated the occurrence of fragmented electrograms as a source of reentrant activity [2]. Formerly, fQRS had already been considered a marker for structural heart diseases (SHD) triggering biventricular hypertrophy [3]. The presence of fQRS can be induced by any condition interrupting with the normally homogeneous depolarisation status in the myocardium and yielding regional conduction decelerating such as ischemia, scar, fibrosis, myofiber disarray, inflammation, and microvascular abnormality [1]. Das et al. revealed that there was a good correlation between fQRS and the presence of myocardial scar in patients with ischemic heart disease (IHD) that appeared by single-photon emission tomography (SPET) [4]. Right ventricle myocardial infarction (RVMI) with or without left ventricular (LV) involvement is a more commonly diagnosed entity regarding the options for treatment evolves [5]. RVMI can occur with or without LV involvement. The incidence of RVMI sharing with inferior wall LV dysfunction ranges from 10 to 50\% [5]. Primarily, the RV gets its arterial blood supply from the right coronary artery (RCA) that releases multiple, small branches to supply the anterior RV before dividing terminally into the acute marginal branch (AM) that runs 
anteriorly along with the diaphragm and the posterior descending artery (PDA). The PDA also supplies the atrioventricular node (AVN) in 90\% of patients, with a branch of the gives off providing flow in the remainder of patients. The PDA supplies the inferior wall of both ventricles and is a terminal branch of the RCA in $85 \%$ of patients but may arise from the left coronary circulation in $15 \%$ of the population [5]. The RV is less susceptible to infarction than the LV. This is due to its thin-walled structure with a decrease in the demand for $\mathrm{O} 2$ and reducing cardiac pressures. Despite these differences, RVMI is most commonly evoked by atherosclerosis [5]. Right-sided ECG is the most sensitive and specific. So, ST-segment elevation in V4R $>1.0 \mathrm{~mm}$ has $100 \%$ sensitivity, $87 \%$ specificity, and $92 \%$ predictive accuracy [5]. RVMI is not infrequent in patients with inferior myocardial infarct (IMI) [6]. Using right-sided precordial leads for early RVMI diagnosis can be helping in giving appropriate treatment and improvement of prognosis [7. When IMI is accompanied by RVMI, more bradycardia, need for pacing, hypotension, and mortality will be possible complications. More than $30 \%$ of patients with IMI also have RVMI, but only $10 \%$ have remarkable hemodynamic instability due to RV dysfunction [6,8]. Ischemia in the RV may be causing systolic and diastolic dysfunction, causing a significant deficit in LV preload with a subsequent decrease in cardiac output (COP) and systemic hypotension [7]. Selective therapies encompasse fluid resuscitation and vasopressors may be indicated promptly [7].

\section{Case presentations}

A 64-year-old married, farmer, heavy smoker, Egyptian male patient presented with acute severe chest pain. Abundant sweating, palpitations, and dizziness were the only associated symptoms. The patient is a smoker of about 30 cigarettes per day for nearly 25 years. He denied a history of cardiovascular diseases, the same attack, drugs, or any other special habits. Chest pain was anginal, compressible, intolerable, and progressive. Informed consent was taken. Upon general physical examination; generally, the patient was anxious, severe sweaty, had cold extremities, with a regular heart rate of $70 \mathrm{bpm}$, blood pressure of $100 / 70 \mathrm{mmHg}$, respiratory rate of $22 \mathrm{bpm}$, the temperature of $36.5^{\circ} \mathrm{C}$, and pulse oximeter of $\mathrm{O} 2$ saturation of $95 \%$. No more relevant clinical data were noted during the clinical examination. He was admitted to the ICU for anginal chest pain. Urgent ECG was done on the ICU admission showing acute inferior (II, III, and aVF) ST-segment elevation myocardial infarction and reciprocal ST-depression changes in leads (I, aVL, V2, and V3). There are QRS fragmentations in I, II, III, aVL, and aVF leads, Wavy triple an ECG sign (Yasser's sign), and AC artifacts (Figure 1A). Right ECG tracing was done within 3 minutes of the initial above tracing showing right ventricular infarction (V3R and V4R leads) (Figure 1B). QRS-complex fragmentations and right ventricular infarction in the presence of inferior infarction with the triple-vessels disease was the most probable diagnosis. $\mathrm{O} 2$ inhalation was given $(100 \%$, by nasal cannula, $5 \mathrm{~L} / \mathrm{min})$. Pethidine HCL $100 \mathrm{mg}$ given on intermittent IV doses. Aspirin 4 chewable oral tablet $(75 \mathrm{mg})$, clopidogrel 4 oral tablet $(75 \mathrm{mg})$, streptokinase IVI (1.5 million units over 60 minutes) were added with follow-up for blood pressure. Clinical improvement and gradual electrocardiographic STsegment (whether elevations or reciprocal ST-depressions) resolution (Figure 1C) had happened. The chest pain starts too resolute during streptokinase infusion. The measured random blood sugar was $169 \mathrm{mg} / \mathrm{dl}$. The troponin test was positive $(88 \mathrm{ng} / \mathrm{L})$. The initial echocardiography was done after hospital discharge within 4 days of the presentation showing LV dilation with both systolic (EF of 49\%) and diastolic dysfunction, mild MR, mild TR, trivial AR, and PHT. (Figure 2A) Later echocardiography was done within 21 days of the presentation showing normal LV and systolic (EF of 56\%; red arrow) mild hypokinetic IVS with the anterolateral wall, and trivial MR. (Figure 2B). The patient had undergone to cardiac catheter within 10 days of presentations which showed atherosclerotic left main artery, atherosclerotic LAD with no obstruction, LCX showed proximal total occlusion, and RCA showed para-ostial to mid-segment $80 \%$ lesion. Three DES were applied. No more workup was done. The patient was continued: aspirin tablet ( $75 \mathrm{mg}$, once daily), clopidogrel tablet $(75 \mathrm{mg}$, once daily), and atorvastatin ( $40 \mathrm{mg}$ once daily) until discharged on the $5^{\text {th }}$ day. Future cardiovascular follow-up was advised.

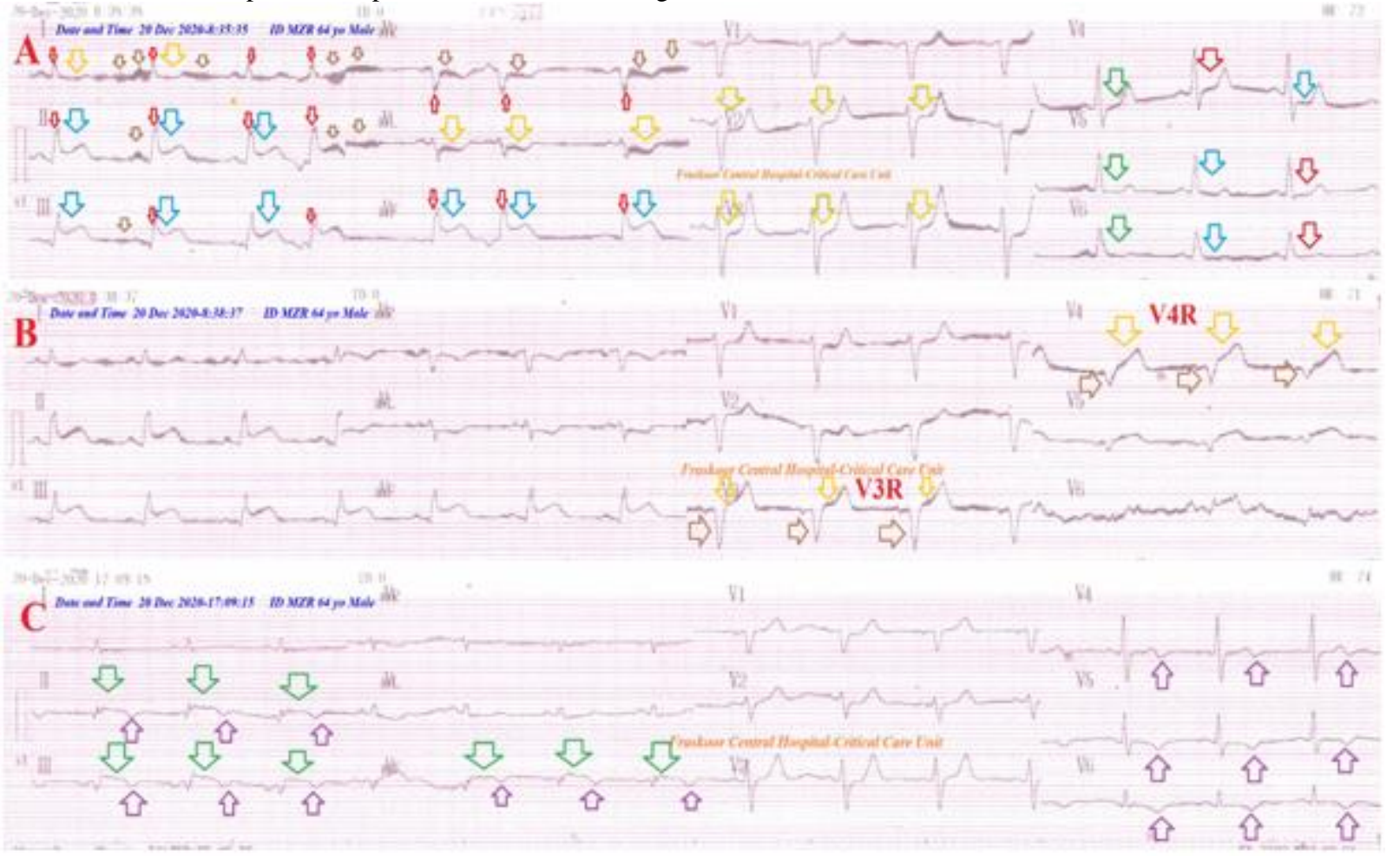

Figure 1: Serial ECG tracings; A. initial tracing was done on the ICU admission showing acute inferior (II, III, and aVF) ST-segment elevation myocardial infarction (blue arrows) and reciprocal ST-depression changes in leads (I, aVL, V2, and V3; orange arrows). There are QRS 
fragmentations in I, II, III, aVL, and aVF; small red arrows), Wavy triple an ECG sign (Yasser's sign; red, blue, and green arrows) and AC artifacts (small brown arrows). B. tracing within 3 minutes of the initial A.tracing showing right ventricular infarction (V3R and V4R leads; orange and brown arrows) C. tracing within 6 hours of the streptokinase IV infusion showing good resolution of ST-segment elevation myocardial infarction in the inferior leads (II, III, and aVF; green arrows) and superficial T-waves inversion changes in leads (II, III, aVF, V2, and V4-6; pink arrows).

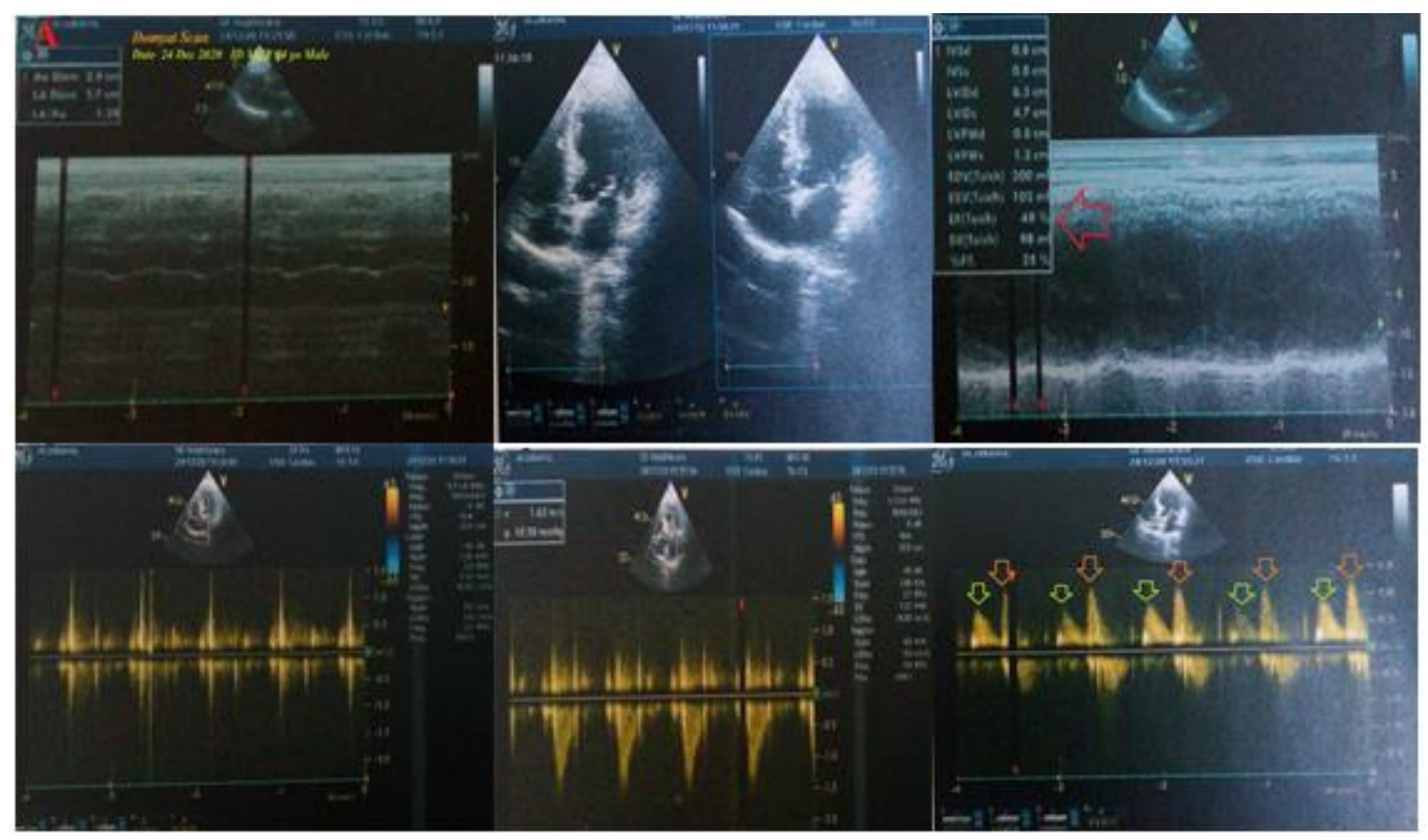

Figure 2A: Echocardiography images were done within 4 days of presentation showing LV dilation with both systolic (EF of $49 \%$; red arrow) and diastolic dysfunction (lime and orange arrows) mild MR, mild TR, trivial AR, and PHT.

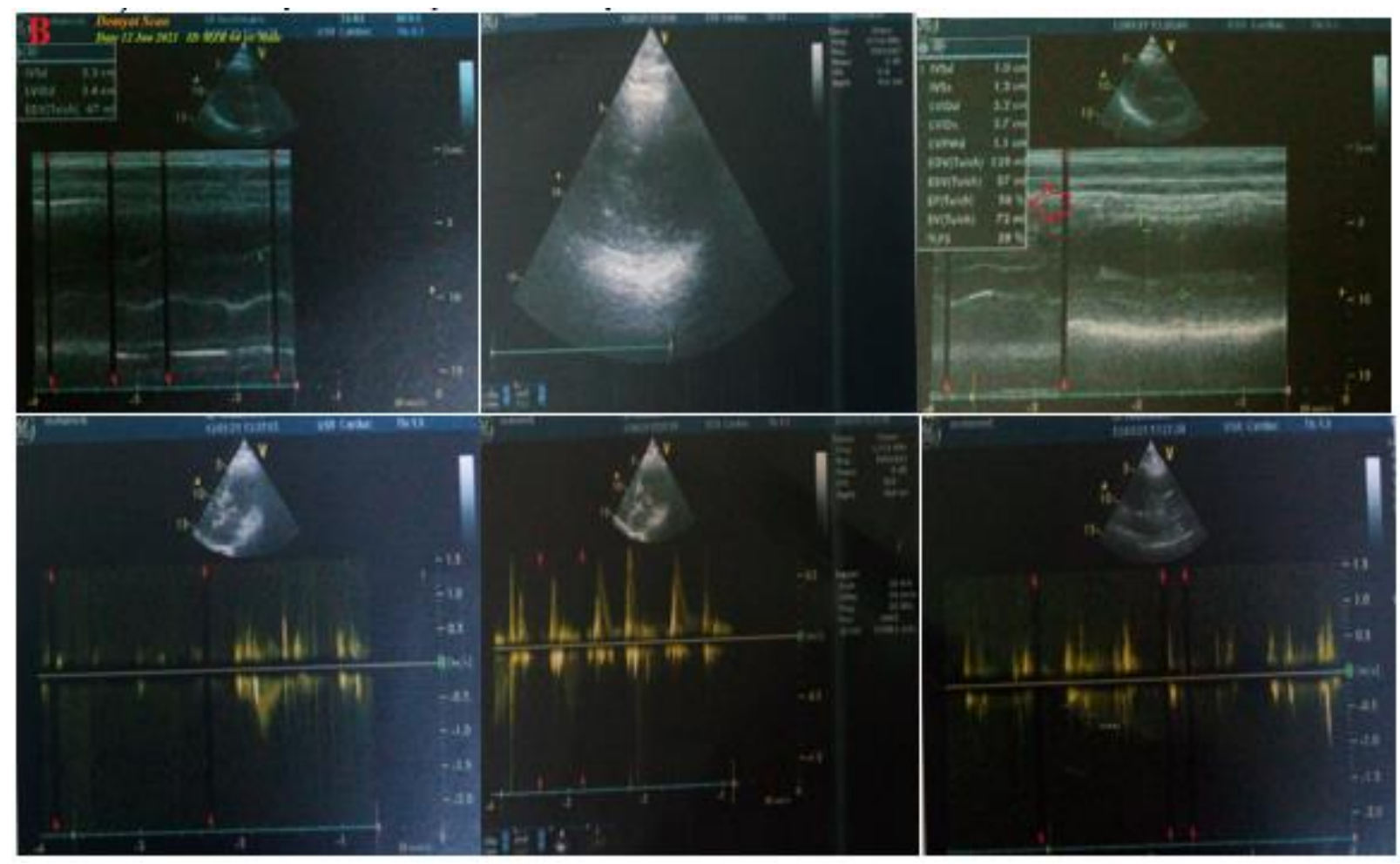

Figure 2B: Echocardiography images were done within 21 days of the presentation showing normal LV and systolic (EF of $56 \%$; red arrow) mild hypokinetic IVS with the anterolateral wall, and trivial MR. 


\section{Discussion}

\section{- Overview:}

- A 64-year-old married, farmer, heavy smoker, Egyptian male patient presented with acute severe chest pain and inferior with right ventricular ST-segment elevation myocardial infarction (STEMI) and fragmentation of the QRS-complex.

- The primary objective for my case study was the presence of a patient who presented with acute severe chest pain, IMI, RVMI, and fragmentation of the QRS-complex in the ICU.

- The secondary objective for my case study was the question of; How did you manage the case at home?

- An existence of right ventricular ST-segment elevation myocardial infarction the presence of inferior infarction indicating the risk of the current ischemic heart disease.

- The borderline blood pressure represents another risk factor in the patient of inferior and right ventricular STEMI.

- The presence of fragmentation of the QRS-complex is considered another risk.

- Dramatic clinical ECG reversal of ST-segment deviations after streptokinase and initial emergency medications is a good prognostic sign.

- The improvement in echocardiography after PTCA and medical treatment strengthen their role in the management of the current case.

- The dramatic response of the above clinical manifestations and changes of CAS only to $100 \% \mathrm{O} 2$ was the target of the study.

- Massive acute pulmonary embolism (APE) is the most possible differential diagnosis for the current case study.

- I can't compare the current case with similar conditions. There are no similar or known cases with the same management for near comparison.

- There are no known limitations of the current study.

\section{Conclusion and Recommendations}

- The presence of fragmentation of the QRS-complex may have a bidirectional impact from seriousness to complications.

- Despite the presence of inferior with right ventricular ST-segment elevation myocardial infarction and QRS-complex fragmentations, but there is no correlation with the severity of the disease.
- Dramatic clinical and electrocardiographic response signifying the role of streptokinase and fibrinolytic.

\section{Acknowledgment}

- The author wishes to thank the critical care unit nurses who make extraECG copies for helping me and my wife to save time and improving the conditions for supporting me.

\section{Conflicts of interest}

There are no conflicts of interest.

\section{References}

1. Brohet C. (2019). Fragmentation of the QRS complex: the latest electrocardiographic craze? Editorial, Acta Cardiologica. 2019;74(3):185-187.

2. Boineau JP, Cox JL. (1973). Slow ventricular activation in acute myocardial infarction. A source of re-entrant premature ventricular contractions. Circulation. 1973;48:702-713.

3. Flowers NC, Horan LG, Thomas JR, et al. (1969). The anatomic basis for high-frequency components in the electrocardiogram. Circulation. 1969;39:531-539.

4. Das MK, Khan B, Jacob S, et al. (2006). Significance of a fragmented QRS complex versus a $\mathrm{Q}$ wave in patients with coronary artery disease. Circulation. 2006;113:2495-2501.

5. Jeffers JL, Boyd KL, Parks LJ. (2021). Right Ventricular Myocardial Infarction. [Updated 2021 Aug 3]. In: StatPearls [Internet]. Treasure Island (FL): StatPearls Publishing; 2021 Jan-.

6. Lisbona R, Sniderman A, Derbekyan V, Lande I, Boudreau R. (1983). Phase and amplitude imaging in the diagnosis of acute right ventricular damage in inferior infarction. Clin Nucl Med. 1983 Nov;8(11):517-520.

7. Ondrus T, Kanovsky J, Novotny T, Andrsova I, Spinar J, Kala P. (2013). Right ventricular myocardial infarction: From pathophysiology to prognosis. Exp Clin Cardiol. 2013 Winter;18(1):27-30.

8. Martin W, Tweddel A, McGhie I, Hutton I. (1989). The evaluation of right ventricular function in acute myocardial infarction by xenon-133. Nucl Med Commun. 1989 Jan;10(1):35-43.

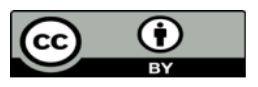

This work is licensed under Creative Commons Attribution 4.0 License

To Submit Your Article Click Here: Submit Manuscript
Ready to submit your research? Choose Auctores and benefit from:

$>$ fast, convenient online submission

$>$ rigorous peer review by experienced research in your field

$>$ rapid publication on acceptance

$>$ authors retain copyrights

$>$ unique DOI for all articles

$>$ immediate, unrestricted online access

At Auctores, research is always in progress.

Learn more https://auctoresonline.org/journals/journal-of-thoracic-diseaseand-cardiothoracic-surgery- 